\title{
Konaklama İşletmelerinin Web Sayfa Tasarımlarının Pazarlama Uygulamaları Açısından İncelenmesi: Eskişehir Örneği*
}

\author{
Arş. Gör. Merve ASMADİLİ \\ Anadolu Üniversitesi, Turizm Fakültesi, Eskişehir \\ e-posta: mervekalyoncu@anadolu.edu.tr
}

\section{Doç. Dr. Gökçe YÜKSEK}

Anadolu Üniversitesi, Turizm Fakültesi, Eskişehir, e-posta: gozer@anadolu.edu.tr

Öz

Eskişehir' de yer alan turizm işletme belgeli konaklama işletmelerinin web sayfaları ile ilgili olan bu araştırmanın amacı, Eskişehir ilinde faaliyet gösteren turizm işletme belgeli konaklama tesislerinin web sayfa tasarımlarının pazarlama uygulamaları açısından incelenmesidir. Bu amaçla Eskişehir'de yer alan konaklama işletmeleri bu çalışmanın evrenini oluştururken, amaçlı örnekleme yöntemiyle turizm işletme belgeli konaklama işletmeleri seçilmiştir. Bu kapsamda web sayfaları incelenerek elde edilen verilere içerik analizi yapılmıştır. Web sayfalarının büyük çoğunluğunda, çevrimiçi yardım formu, döviz kuru bilgisi, çevrimiçi anket, öneri formu ve ziyaretçi defteri gibi özelliklere sahip olmadığg saptanmıştır. Bu bulgulardan hareketle, konaklama işletmeleri web sayfalarının daha etkileşimli olmasına ve pazarlama uygulamalarının etkin kullanılmasına dikkat edilmesi gerektiği söylenebilir.

Anahtar Kelimeler: Konaklama İşletmeleri, Web Sayfa Tasarımı, Pazarlama Uygulamaları, Eskişehir. * Bu çalışma 18. Ulusal Turizm Kongresinde bildiri olarak sunulmuştur.

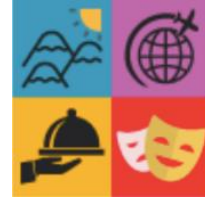

Türk Turizm Araştırmaları Dergisi Cilt.2, Sayı.1, 2018

ss.15-26.

DOI: $10.26677 /$ tutad.2018.21

\section{Önerilen Atıf:}

Asmadili, M. ve Yüksek, G. (2018). Konaklama İşletmelerinin Web Sayfa Tasarımlarının Pazarlama Uygulamaları Açısından İncelenmesi: Eskişehir Örneği, Türk Turizm Araştırmaları Dergisi, Cilt.2, Sayı.1, ss.15-26. 


\title{
Analysis of Website Designs of Hotels in Terms of Marketing Practices: Eskisehir Example
}

\author{
Research Assistant Merve ASMADİLI \\ Anadolu University, Faculty of Tourism, Eskisehir \\ e-mail: mervekalyoncu@anadolu.edu.tr
}

Associate Prof. Dr. Gökçe YÜKSEK

Anadolu University, Faculty of Tourism, Eskisehir

e-mail: gozer@anadolu.edu.tr

\begin{abstract}
The purpose of this research is analyzing website of the hotels which have tourism management certificate in Eskisehir in terms of marketing practices. For this purpose, while hotels in Eskisehir represent the universe of this study, hotels which have tourism management certificate have been selected by purpose sampling method. Within this scope, websites were analyzed and content analysis was used. The majority of website have not had features such as online help form, exchange rate information, online questionnaire, proposal form, and visitor book. From these findings, it can be said that attention should be paid to the fact that the websites of the hotels should be more active and that marketing practices are used effectively.
\end{abstract}

Keywords: Hotels, Website Design, Marketing Practices, Eskisehir.

\section{Suggested Citation:}

Asmadili, M. and Yüksek, G. (2018). Analysis of Website Designs of Hotels in Terms of Marketing Practices: Eskisehir Example, Journal of Turkish Tourism Research, Vol.2, Issue.1, pp.15-26. 


\section{Gíriş}

Bilgi teknolojilerinde yaşanan gelişmeler, iletişim süreçlerinde önemli değişimleri beraberinde getirmiştir. Yaşanan bu değişim, bilgilerin daha hızlı paylaşılmasına ve sınırların ortadan kalkarak, mesafelerin önemini yitirmesine yol açmıştır. Bu gelişmeler, pek çok sektöre canlılık kazandırmış, internet sayesinde ürün ve hizmet pazarlamasında maliyetler azaltılmış, etkileşimli bir ortam yaratılmış ve süreçler hızlanmıştır. Tüm bu avantajlar, özellikle hizmetlerin pazarlandığı işletmelerden oluşan turizm endüstrisinde zaman maliyetinin düşürülmesine yardımcı olmaktadır (Ateş ve Boz, 2015: 63).

Konaklama işletmelerinde verilerin hızlı ve verimli bir şekilde değerlendirilmesi gerekliliği; verilerin elektronik ortamda işlenmesini zorunlu kılmıştır. Konaklama işletmeleri, web sayfalarında, potansiyel tüketicileri cezbedecek özellikleri ön plana çıkarmaya odaklanmışlardır. Bu özellikler, konaklama işletmelerinin sahip oldukları ürün ve hizmetler başta olmak üzere, pazarlama faaliyetlerine yer veren çeşitli bilgi, özellik ve hizmetleri içerebilmektedir (Karamustafa ve Öz, 2010: 192). Son yıllarda yapılan araştırmalar, seyahat etmeden önce bilgi aramak için en çok kullanılan kanalın internet olduğunu ve internetin seyahat kararı vermede önemli kaynaklardan biri haline geldiğini göstermektedir (Lee, 2009; Chow ve Murphy, 2011; Hosany ve Prayag, 2013; Marmo ve Baggio, 2017; Pesonen ve Pasanen, 2017; Muhoho-Minni ve Lubbe, 2017). Web sayfaları, özellikle turizm sektöründe konaklama işletmeleri tarafından en yaygın kullanılan pazarlama araçlarından biri olmuştur. Web sayfaları aracılığıyla, potansiyel müşterilerinin sorularını ve isteklerini karşılayabilen, doğrudan rezervasyon taleplerini en uygun, en hızlı ve güvenli biçimde yerine getiren konaklama işletmeleri, pazardaki rekabet güçlerini arttırabilme şansı yakalamaktadırlar. Dolayısıyla konaklama işletmelerinin, web sayfa tasarımına daha fazla özen göstermeleri gerekmektedir (Güllü ve Kabasakal, 2016: 304).

$\mathrm{Bu}$ araştırmanın amac1, Eskişehir ilinde faaliyet gösteren turizm işletme belgeli konaklama tesislerinin web sayfa tasarımlarının pazarlama uygulamaları açısından incelenmesidir. $\mathrm{Bu}$ amaç doğrultusunda, konaklama işletmelerinin web sayfaları incelenerek mevcut durum değerlendirilmesi yapılmıştır. Turizm sektöründe, müşterilerin genellikle satın alacakları hizmetleri önceden görme ve deneme imkânları olmadığı için işletmenin web sayfasında yer alan özellikler ve güncel bilgiler önem 
kazanmaktadır. Bu yönüyle çalışmanın hem alanyazına hem de konaklama işletmelerine farkındalık kazandıracağı düşünülmektedir.

\section{İLGILII ALANYAZIN}

Geleneksel pazarlama anlayışında, bir hizmeti satın almada karar verme davranışında etkili olan unsurlar arasında; dost-akraba tavsiyesi ya da o hizmetten daha önce yararlanmış olma durumu söz konusudur. Günümüzde konaklama işletmelerinin etkin pazarlama faaliyetleri gerçekleştirmelerinin bir zorunluluk haline geldiği konusu düşünüldüğünde, yeni teknoloji ve pazarlama yaklaşımlarına uyum sağlanması gerektiği sonucu ortaya çıkmaktadır. Bugün teknolojinin geldiği noktada, pazarlama uygulamalarının da teknoloji ile beraber geliştiğini görmek mümkündür (Haas, 2002, 637). Teknolojinin imkânlarından yararlanarak bilgiyi üretebilen, etkileşimli olarak paylaşabilen toplumlar, rekabet gücü yüksek toplumlar olarak değerlendirilmektedir. Günümüzde rekabet; bilginin değerlendirilme yeteneğine bağlı olarak değişken bir yapıya sahiptir. Bu değişim sayesinde bilgi, ekonominin ve pazarlamanın temel kaynağı haline gelmiştir (Çubukçu, 2010: 39). Kline, Morrison ve St. John (2004)'ün konaklama işletmelerinin web sayfalarını incelediği araştırmada; kullanıcı dostu bir web sayfası tasarımı, web sayfasının çekiciliği ve pazarlama etkinliği ve teknik özellikler olmak üzere dört boyut ortaya konmuştur. Ayrıca web sayfalarının çekiciliklerini kullanmada başarılı olduklarını, ancak diğer özelliklerinin geliştirmesi gerektiği sonucuna varılmıştır.

Teknolojik yeniliklerle birlikte ortaya çıkan en önemli unsurlardan biri internettir. İnternetin bir bilgi değerlendirme ortamı olarak kullanılması, pazarlama faaliyetlerinde interneti kullanmayı beraberinde getirmiştir. Bilginin depolanabilmesi, sınıflandırılabilmesi ve kullanılabilmesi mümkün hâle geldiğinde, internet, pazarlama faaliyetleri için uygun ortam sağlayan bir mecraya dönüşmüştür (Boylu ve Tuncer, 2008: 12; Başfırınc1, 2008: 55-56).

Konaklama sektöründe internetin doğrudan bir dağıtım kanalı olarak kullanılmaya başlanmasıyla, web sayfalarının oluşturulması, müşteri ile işletme arasındaki duvarların kaldırılması işletmelerin başarısında kritik rol oynamaktadır (Jeong, Oh ve Gregoire, 2003: 162). Bilgi teknolojilerinin gelişmesi ile birlikte; potansiyel müşteri, bilgiyi anında ve oturduğu yerden bilgisayar ekranında görebileceği ve karşılaştırma yapabileceği gibi isteğine göre rezervasyon yapabilmektedir. Bu durum, söz konusu müşterinin satın alma kararında doğrudan etkilidir (Sarı ve Kozak, 2005: 253). 
Türkiye'de konaklama işletmelerinin web sayfalarının değerlendirildiği çalışmalara bakıldığında, araştırmacıların farklı bakış açıları ile konuyu ele aldıkları görülmektedir. Karamustafa vd., (2002) Türkiye'de faaliyet gösteren konaklama işletmelerinin pazarlama faaliyetlerinde turizm aracılarına bağımlı olmaları nedeniyle sahip oldukları web sayfalarının, sadece tanıtım amaçlı ve etkileşimsiz bir özellik taşıdığını söylemişlerdir. Güzel vd., (2014) yaptıkları çalışmada, konaklama işletmelerinin pazarlama aracı olarak web sayfalarında yer alan rekreasyon faaliyetlerinin; su sporları, spor aktiviteleri, eğlence, oyun etkinlikleri, bakım ve rehabilitasyon, animasyon, çocuk etkinlikleri ve kurs etkinlikleri olmak üzere sekiz tema altında toplandığını belirlemişlerdir. Özer (2015)'in çalışmasında İstanbul'da faaliyet gösteren 81 adet beş yıldızlı otel işletmesinin kurumsal web sitelerinde yer verdikleri müşteri sadakat programları incelenmiş ve büyük çoğunluğunun sadakat programları uyguladığı, bu programların özel bir isme ve farklı kart seçeneklerine sahip oldukları belirlenmiştir.

Konaklama işletmelerinin web sayfalarının incelendiği çalışmalarla ilgili genelleme yapmak gerekirse, web sayfalarında; konaklama işletmesinin ürün ve hizmetlerine dair çok fazla bilginin var olduğu görülmüştür. Bu geniş bilgi yelpazesi içinden pazarlama açısından en doğru bileşene ulaşmak ciddi bir problemdir. Üstelik teknolojik gelişmeler bu problemi azaltmamakta, aksine yeni boyut ve özellikleri gündeme getirerek çözümü daha da zorlaştırmaktadır (Pfaffenberg ve Burnett, 2007: 54). Bu kapsamda, sektöre ait özelliklerin ve teknolojik gelişmelerin de dikkate alınarak, tüketici değerlendirmelerinin ön planda tutulduğu çalışmalara sürekli ihtiyaç duyulmaktadır.

\section{YÖNTEM}

Araştırmanın modeli, tarama modellerinden tekil tarama modelidir. Betimsel bir araştırmadır. Araştırmanın evrenini Eskişehir'de yer alan bütün konaklama işletmeleri oluşturmaktadır. Bu kapsamda, amaçlı örneklem yöntemiyle T.C. Kültür ve Turizm Bakanlığı' nın internet sitesinde yer alan 30 Haziran 2017 tarihli Eskişehir'deki güncel turizm işletme belgeli 33 konaklama işletmesi seçilmiştir. Bu çalışmada örneklemi oluşturan 33 konaklama işletmesinden ikisinin web sayfasının bulunmamasından dolayı, analiz 31 konaklama işletmesinin web sayfaları üzerinden yapılmıştır. Web sayfaları, Baloglu ve Pekcan'ın 2006 yılında kullandığı ölçek uyarlanarak değerlendirilmiştir. Ölçeğin orijinalinde 45 özellik vardır ancak, ölçek uyarlaması yapılırken birçok maddenin aynı anlama gelmesi sebebiyle 38 madde kullanılmıştır. Ölçek maddeleri; Etkileşim, Navigasyon, İşlevsellik ve Pazarlama Uygulamaları olmak üzere dört boyut altında toplanmıştır. Buna göre; Etkileşim boyutu altına ele alınan 
maddeler; telefon, adres, e-mail, çevrimiçi yardım formu, takvim, döviz kuru, çevrimiçi anket, öneri formu ve ziyaretçi defteridir. Navigasyon boyutu altında ele alınan maddeler; diğer linkler, diğer hizmetler, kolay navigasyon, link köprüleri, dizin ve sayfanın ziyaret edilme sayısı olarak sıralanabilir. İşlevsellik boyutunda yer alan maddeler; kurumsal kimlik, arka plan rengi, arka plan görüntüsü, video, ses, güncelleme tarihi, banner, sayfa kaydırma zorunluluğu, kolay indirme, yenilik, bilgi çeşitliliği, dil seçeneği ve animasyonlardır. Son olarak Pazarlama Uygulamaları boyutu altında; otelin resmi, oda resmi, promosyon, ürün ve hizmetlerin tanıtımı, otelin haritası, çeorimiçi rezervasyon, turist bilgilendirme, fiyat bilgisi ve sosyal medyadır. Sosyal Medya maddesi ölçeğin orijinalinde yer almazken, bu çalışmada kullanılmıştır.

Etkileşim boyutu altında yer alan e-mail linki maddesi, diğer e-mail maddesi ile aynı anlama geldiğinden çıkarılmıştır. Navigasyon boyutu altında yer alan doğru navigasyon maddesi kolay navigasyonla hemen hemen aynı anlama geldiğinden ölçeğe alınmamıştır. İşlevsellik boyutu altında yer alan indirme imkânları, ayrıntılı bilgi ve siteye erişim kolaylı̆̆ maddeleri, aynı boyut altında yer alan maddelerle aynı anlama geldiğinden kullanım dışı bırakılmıştır. Son boyut olan Pazarlama Uygulamaları boyutunda ise resimlerin kalitesi, yazlların kalitesi, online ödeme ve e-mail ile rezervasyon maddeleri kullanılmamıştır.

Otel işletmelerinin web sayfalarının tasarım özellikleri ve pazarlama uygulamalarını değerlendirmeyi amaçlayan bu çalışmada nitel bir analiz olan içerik analizi tekniği kullanılmıştır. Veriler; Var (1) ve Yok (2) şeklinde kodlanmıştır. Buna göre konaklama işletmelerinin web sayfalarında yer alan özellikler sıklığına ve yüzdesine göre değerlendirilmiştir.

\section{BULGULAR}

Araştırmanın ölçeği dört boyuttan oluşmaktadır. İlk olarak, konaklama işletmelerinin web sayfalarının Etkileşim Özellikleri, ikinci olarak web sayfalarının Navigasyon Özellikleri, üçüncü boyut olarak İşlevsellik Özellikleri ve dördüncü ve son boyut olarak da Pazarlama Uygulamalarına ilişkin bulgular elde edilmiş ve tartışılmıştır. Bu kapsamda web sayfalarının sahip olduğu özellikler, içerik ve içeriklerin niteliği açısından değerlendirilmiştir.

Eskişehir'de yer alan işletme belgeli konaklama işletmelerinin web sayfalarının Etkileşim Özelliklerine ilişkin veriler Tablo 1'de yer almaktadır. Buna göre, 31 konaklama işletmesinin hiç birinin web sayfalarında döviz kuru bilgisine yer vermediği, 31 
konaklama işletmesinin yalnızca bir tanesinin çevrimiçi ankete sahip olduğu ve yalnızca iki tanesinin öneri formuna sahip olduğu saptanmıştır.

Tablo 1. Web Sayfalarının Etkileşim Özelliklerine İlişkin İfadelerin Sıklık-Yüzde Değerleri

\begin{tabular}{|c|c|c|c|c|c|c|c|c|}
\hline \multicolumn{3}{|c|}{ Telefon } & \multicolumn{3}{|c|}{ Adres } & \multicolumn{3}{|c|}{ e-mail } \\
\hline & Siklik & Yüzde & & Siklik & Yüzde & & Siklik & Yüzde \\
\hline \multirow[t]{2}{*}{ Var } & 31 & 100,0 & Var & 31 & 100,0 & Var & 29 & 93,5 \\
\hline & & & & & & Yok & 2 & 6,5 \\
\hline \multicolumn{3}{|c|}{ Çevrimiçi Yardım Formu } & \multicolumn{3}{|c|}{ Takvim } & \multicolumn{3}{|c|}{ Döviz Kuru } \\
\hline & Siklik & Yüzde & & Siklik & Yüzde & & Siklik & Yüzde \\
\hline Var & 12 & 36,4 & Var & 28 & 84,8 & & & \\
\hline Yok & 21 & 63,6 & Yok & 5 & 15,2 & Yok & 31 & 100,0 \\
\hline \multicolumn{3}{|c|}{ Çevrimiçi Anket } & \multicolumn{3}{|c|}{ Öneri Formu } & \multicolumn{3}{|c|}{ Ziyaretçi Defteri } \\
\hline & Siklik & Yüzde & & Siklik & Yüzde & & Siklik & Yüzde \\
\hline Var & 1 & 3,2 & Var & 2 & 6,5 & Var & 5 & 16,1 \\
\hline Yok & 30 & 96,8 & Yok & 29 & 93,5 & Yok & 26 & 83,9 \\
\hline
\end{tabular}

Eskişehir'de yer alan işletme belgeli konaklama işletmelerinin web sayfalarının Navigasyon Özellikleri'ne ilişkin veriler Tablo 2'de yer almaktadır. Buna göre, 31 konaklama işletmesinin tamamının web sayfalarında kolay gezinme imkânı bulunduğu, 28 konaklama işletmesinin; web sayfalarında diğer linklere, diğer hizmetlere ilişkin yönlendirmelere ve dizine yer verdiği saptanmıştır. Bununla beraber 29 konaklama işletmesinin web sayfasında, sayfanın kaç kez ziyaret edildiğine dair bir sayaç bulunmadığı görülmüştür.

Tablo 2. Web Sayfalarının Navigasyon Özelliklerine İlişkin İfadelerin Sıklık-Yüzde Değerleri

\begin{tabular}{|c|c|c|c|c|c|c|c|c|}
\hline \multicolumn{3}{|c|}{ Diğer Linkler } & \multicolumn{3}{c|}{ Diğer Hizmetler } & \multicolumn{3}{c|}{ Kolay Navigasyon } \\
\hline & S1klık & Yüzde & & S1klık & Yüzde & & S1klı & Yüzde \\
\hline Var & 28 & 90,3 & Var & 28 & 90,3 & Var & 31 & 100,0 \\
\hline Yok & 3 & 9,7 & Yok & 3 & 9,7 & & & \\
\hline \multicolumn{3}{|c|}{ Link Köprüleri } & \multicolumn{3}{|c|}{ Dizin } & \multicolumn{3}{|c|}{$\begin{array}{r}\text { Sayfanın Ziyaret } \\
\text { Edilme Sayısı }\end{array}$} \\
\hline & S1klık & Yüzde & & S1klık & Yüzde & & S1klık & Yüzde \\
\hline Var & 26 & 83,9 & Var & 28 & 90,3 & Var & 2 & 6,5 \\
\hline Yok & 5 & 16,1 & Yok & 5 & 9,7 & Yok & 29 & 93,5 \\
\hline
\end{tabular}


Tablo 3. Web Sayfalarının İşlevsellik Özelliklerine İlişkin İfadelerin Sıklık-Yüzde Değerleri

\begin{tabular}{|c|c|c|c|c|c|c|c|c|}
\hline \multicolumn{3}{|c|}{$\begin{array}{c}\text { Kurumsal } \\
\text { Kimlik }\end{array}$} & \multicolumn{3}{|c|}{ Arka Plan Rengi } & \multicolumn{3}{|c|}{$\begin{array}{l}\text { Arka Plan } \\
\text { Görüntüsü }\end{array}$} \\
\hline & Siklık & Yüzde & & Siklik & Yüzde & & Siklık & Yüzde \\
\hline Var & 29 & 97,0 & Var & 16 & 51,6 & Var & 14 & 45,2 \\
\hline Yok & 2 & 3,0 & Yok & 15 & 48,4 & Yok & 17 & 54,8 \\
\hline \multicolumn{3}{|c|}{ Video } & \multicolumn{3}{|c|}{ Ses } & \multicolumn{3}{|c|}{$\begin{array}{c}\text { Güncelleme } \\
\text { Tarihi }\end{array}$} \\
\hline & Siklık & Yüzde & & Siklik & Yüzde & & Siklık & Yüzde \\
\hline Var & 10 & 32,3 & Var & 9 & 29,0 & Var & 17 & 54,8 \\
\hline Yok & 21 & 67,7 & Yok & 22 & 71,0 & Yok & 14 & 45,2 \\
\hline \multicolumn{3}{|c|}{ Banner } & \multicolumn{3}{|c|}{$\begin{array}{c}\text { Sayfa Kaydırma } \\
\text { Zorunluluğu }\end{array}$} & \multicolumn{3}{|c|}{ Kolay İndirme } \\
\hline & Siklik & Yüzde & & Siklik & Yüzde & & Siklik & Yüzde \\
\hline Var & 7 & 22,6 & Var & 22 & 71,0 & Var & 25 & 80,6 \\
\hline Yok & 24 & 77,4 & Yok & 9 & 29,0 & Yok & 6 & 19,4 \\
\hline \multicolumn{3}{|c|}{ Yenilik } & \multicolumn{3}{|c|}{ Bilgi Çeşitliliği } & \multicolumn{3}{|c|}{ Dil Seçeneği } \\
\hline & Siklık & Yüzde & & Siklik & Yüzde & & Siklik & Yüzde \\
\hline Var & 28 & 90,3 & Var & 29 & 93,5 & Var & 21 & 67,7 \\
\hline Yok & 3 & 9,7 & Yok & 2 & 6,5 & Yok & 10 & 32,3 \\
\hline \multicolumn{3}{|c|}{ Animasyonlar } & & & & & & \\
\hline & Siklık & Yüzde & & & & & & \\
\hline Var & 24 & 77,4 & & & & & & \\
\hline Yok & 7 & 22,6 & & & & & & \\
\hline
\end{tabular}

Eskişehir'deki konaklama işletmelerinin web sayfalarının İşlevsellik Özelliklerine ilişkin veriler Tablo 3'te görülmektedir. Buna göre 29 konaklama işletmesi web sayfalarında kurumsal kimliklerine ilişkin bilgilere yer vermekte, 29 konaklama işletmesi web sayfalarında işletmeye dair bilgi çeşitliliğine yer vermektedir. Ayrıca 28 konaklama işletmesinin web sayfasında yeniliklere ilişkin bilgilendirmelerin olduğu görülmüştür.

Eskişehir'de bulunan konaklama işletmelerinin web sayfalarının Pazarlama Uygulamalarına ilişkin veriler ise Tablo 4'te yer almaktadır. Buna göre, 31 konaklama işletmesinin tamamının web sayfalarında; oda resimleri, ürün ve hizmetlerin tanıtımı ve konaklama işletmesinin haritasına ilişkin bilgilere sahip olduğu saptanmıştır. 22 konaklama işletmesinin ise sosyal medyayı kullandığı belirlenmiştir. 
Tablo 4. Web Sayfalarının Pazarlama Uygulamalarına İlişkin Ifadelerin Sıklık-Yüzde Değerleri

\begin{tabular}{|c|c|c|c|c|c|c|c|c|}
\hline \multicolumn{3}{|c|}{ Otelin Resmi } & \multicolumn{3}{|c|}{ Oda Resmi } & \multicolumn{3}{|c|}{ Promosyon } \\
\hline & Siklik & Yüzde & & Siklık & Yüzde & & Siklik & Yüzde \\
\hline Var & 29 & 93,5 & Var & 31 & 100,0 & Var & 27 & 87,1 \\
\hline Yok & 2 & 6,5 & & & & Yok & 4 & 12,9 \\
\hline \multicolumn{3}{|c|}{$\begin{array}{c}\text { Ürün ve Hizmetlerin } \\
\text { Tanıtımı }\end{array}$} & \multicolumn{3}{|c|}{ Otelin Haritası } & \multicolumn{3}{|c|}{ Çevrimiçi Rezervasyon } \\
\hline & Siklık & Yüzde & & Siklık & Yüzde & & Siklik & Yüzde \\
\hline \multirow[t]{2}{*}{ Var } & 31 & 100,0 & Var & 31 & 100,0 & Var & 26 & 83,9 \\
\hline & & & & & & Yok & 5 & 16,1 \\
\hline \multicolumn{3}{|c|}{ Turist Bilgilendirme } & \multicolumn{3}{|c|}{ Fiyat Bilgisi } & \multicolumn{3}{|c|}{ Sosyal Medya } \\
\hline & Siklık & Yüzde & & Siklik & Yüzde & & Siklik & Yüzde \\
\hline Var & 27 & 87,1 & Var & 26 & 83,9 & Var & 22 & 71,0 \\
\hline Yok & 4 & 12,9 & Yok & 5 & 16,1 & Yok & 9 & 29,0 \\
\hline
\end{tabular}

Eskişehir'de yer alan konaklama işletmelerinin web sayfaları genel olarak değerlendirildiğinde;

- Etkileşim özellikleri bakımından yetersiz,

- Navigasyon özellikleri açısından yeterli fakat bazı konularda eksik,

- İşlevsellik açısından yetersiz ve

- Pazarlama uygulamaları sıklık olarak bakıldığında yeterli gibi görünse de içerik olarak yetersiz bulunmuştur.

\section{SONUÇ VE ÖNERILLER}

Elde edilen bulgular değerlendirildiğinde, Eskişehir'de yer alan turizm işletme belgeli konaklama işletmelerinin web sayfalarının etkileşim açısından değerlendirildiğinde, etkileşim düzeylerinin düşük olduğu söylenebilir. Web sayfalarının büyük çoğunluğunun; çevrimiçi yardım formu, döviz kuru bilgisi, çevrimiçi anket, öneri formu ve ziyaretçi defteri gibi özelliklere sahip olmadığı görülmüştür. Döviz kurunun olmaması, Bayram'ın 2008 yılında Türkiye'deki konaklama işletmelerinin web sayfalarını incelediği çalışmasının sonucuyla benzerlik göstermektedir. Bu çalışmanın sonuçlarına göre, döviz çeviricisi ve bilgisi, sıkça sorulan sorular, farklı ödeme seçeneği, rezervasyon hattı gibi özelliklerin web sayfalarında bulunmadığ1 ortaya konmuştur. Bunların içinden özellikle çevrimiçi anket, öneri formu ve ziyaretçi defteri unsurlarının müşteri ile konaklama işletmesinin arasındaki önemli bir etkileşim kurma aracı olduğu 
söylenebilir. Konaklama işletmeleri, bu kanallar sayesinde müşterilerden aldıkları geri bildirimle kendilerini ve hizmetlerini yenileyebilmekte, hatalarını giderebilmekte ve verimliliklerini arttırabilmektedirler. Diğer taraftan müşteriler de bu kanallar yardımı ile konaklama işletmesinden beklentilerini, şikâyetlerini işletmeye aktarabilmekte ve diğer müşterilerin görüş ve önerilerine ulaşarak konaklama kararı verebilmektedirler. Bu nedenle bir konaklama işletmesinin çevrimiçi anket, öneri formu ve ziyaretçi defteri gibi özelliklere sahip olması, işletme-müşteri etkileşimi açısından önemlidir.

Navigasyon boyutunda yer alan özelliklere bakıldığında, web sayfalarının 29'unda; sayfanın kaç kez ziyaret edildiğine dair bir sayaç bulunmadığı görülmüştür. Sayfanın ziyaret edilme sayısı, işletmenin popülerlik algısı açısından önemli bir gösterge olabilir. Bu da, konaklama işletmesinin imajı üzerinde olumlu bir katkı yaratabilir.

İşlevsellik boyutuna göre, konaklama işletmelerinin, çekiciliği arttırmak, görsel ve işitsel duyulara hitap etmek için video, ses ve banner gibi özellikleri daha sık kullanması önerilmektedir. İyi tasarlanmış bir web sayfası müşterinin kararında önemli bir role sahip olabilmektedir.

İncelenen web sayfalarının pazarlama uygulamalarına bakıldığında; işletmelerden 22 'sinin sosyal medya hesaplarına erişim verdikleri görülmüştür. Günümüzde sosyal medya araçlarının popülerliği ve kullanım sıklığı düşünülecek olursa işletmelerin web sayfalarının sosyal medya araçlarının bağlantılarını vermeleri pazarlama açısından önemlidir. Müşteri sosyal medya bağlantılarına tıkladığı zaman aktif kullanılan bir araç ile karşılaşabilmelidir. Bu sebeple sosyal medya araçları aktif olmayan işletmelerin bu araçları aktif ve güncel hale getirmeleri önerilmektedir. Ayrıca pazarlama uygulamalarından turist bilgilendirme özelliğine bakıldığında işletmelerin neredeyse tamamında bu bilgilerin bulunduğu fakat kapsamlı olmadığı görülmüştür. Potansiyel müşteriler, destinasyon hakkında web sayfasından edineceği bilgiler ile konaklama kararı verebilmektedir. Özellikle destinasyonlarda bulunan çekicilik unsurlarının bu bilgiler kapsamına alınması önerilmektedir. Örneğin, Eskişehir'in sahip olduğu somut ve somut olmayan kültürel mirasına ilişkin daha kapsamlı bilgilere yer verilebilir. $\mathrm{Bu}$ aynı zamanda destinasyon imajı üzerinde olumlu etki yaratabilir.

Web sayfaları, zengin bir bilgi kaynağı olarak düşünüldüğünde, tasarım özelliklerinin, görsel araçların ve bilgilerin sürekli güncellenmesi gerekliliği ortaya çıkmaktadır. Bu güncelleme yapılırken konaklama işletmeleri, hitap ettikleri pazar bölümlerini iyi tanımalı ve web sayfalarını müşterilerin özeliklerine göre tasarlamalıdırlar. Analiz sonuçları değerlendirildiğinde Eskişehir'de yer alan konaklama işletmelerinin web sayfalarının ihtiyaca ve müşteri profiline göre yeniden tasarlanması önerilmektedir. 
Diğer taraftan müşterinin web sayfası üzerinden çevrimiçi alışveriş yapabilme imkânı da önemli bir husustur. Kline, Morrison ve St. John, 2004 yılında yaptıkları çalışmalarında çevrimiçi alışverişin web sayfalarına dâhil edilmesinin önemini vurgulayarak, çevrimiçi alışveriş imkânının olduğu bir web sayfasının potansiyel müşterileri daha uzun süre web sayfasında gezinmeye teşvik edebileceğini belirtmişlerdir.

\section{KAYNAKÇA}

Akçi, Y. ve Olcay, A. (2014). Otel İşletmelerinin Pazarlama Faaliyetlerinin Yönetici Görüşleriyle İncelenmesi Üzerine Bir Araştırma (Gaziantep ve Adıyaman Örneği). Sosyal ve Beşeri Bilimler Araştırmaları Dergisi, (32):78-94.

Baloglu, S. ve Pekcan, Y. A. (2006). The Website Design and Internet Site Marketing Practices of Upscale and Luxury Hotels in Turkey. Tourism Management, 27(1):171-176.

Başfırıncı, Ç. (2008). Bir Pazarlama İletişim Medyası Olarak Web Ortamında İçerik Analizi Yapmanın Güçlükleri ve Olası Çözüm Önerileri, Yönetim, 19(61):52 - 71.

Bayram. M. (2008). Elektronik Ticarette Web Site Tasarımının Önemi: Türkiye Otel Web Sitelerinin Değerlendirilmesi, (Yayımlanmamış Yüksek Lisans Tezi), Gazi Üniversitesi, Eğitim Bilimleri Enstitüsü, Ankara.

Boylu, Y. ve Tuncer A. (2008). Konaklama İşletmelerinin Yönetim Yapılarının Web Tabanlı Pazarlama Faaliyetlerine Etkisi Üzerine Bir Araştırma, İstanbul Ticaret Üniversitesi Sosyal Bilimler Dergisi, 7(13):11-30.

Chow, I. and Murphy, P. (2011). Predicting Intended and Actual Travel Behaviors: An Examination of Chinese Outbound Tourists to Australia. J. Travel Tourism Mark. 28: 318330.

Çubukçu, İ. M. (2010). Konaklama İşletmeleri Web Site İçeriklerinin Değerlendirilmesi, İnternet Uygulamaları ve Yönetimi Dergisi, (1):39- 59.

Güzel, F. Ö., Türker, G. Ö. ve Türker, A. (2014). Bir Pazarlama Enstrümanı Olarak Rekreasyon Faaliyetlerinin Otellerin Web Sitelerinde Kullanımı: Antalya Destinasyonunda Bir Araştırma. Journal of Internet Applications and Management/Internet Uygulamaları ve Yönetimi Dergisi, 5(2): 5-18.

Haas, R. (2002). The Austrian Country Market: A European Case Study on Marketing Regional Products and Services in a Cyber Mall, Journal of Business Research, 55 (8):637664. 
Hosany, S. and Prayag, G. (2013). Patterns of Tourists' Emotional Responses, Satisfaction, and Intention to Recommend. J. Business Res. 66:730-737.

Jeong, M., Oh. H. and Gregoire, M. (2003). Conceptualizing Web Site Quality and Its Consequences in the Lodging Industry, Hospitality Management, (22):161 - 175.

Karamustafa, K. ve Öz, M. (2010). Türkiye'de Konaklama İşletmelerini Web Sitelerinde Yer Verilen Faktörlerin Başarımı, Eskişehir Osmangazi Üniversitesi, İIBF Dergisi, 5(2):189218.

Karamustafa, K., Biçkes, D.M. ve Ulama, Ş. (2002). Türkiye'deki Konaklama İşletmelerinin İnternet Web Sitelerini Değerlendirmeye Yönelik Bir Çalışma, Erciyes Üniversitesi İktisadi ve İdari Bilimler Fakültesi Dergisi, (19):51-92.

Kline, S. F., Morrison, A. M. and St. John, A. (2004). Exploring Bed and Breakfast Websites: A Balanced Scorecard Approach. Journal of Travel and Tourism Marketing, 17(23):253-267. doi:10.1300/J073v17n02_19.

Lee, T.H. (2009). A Structural Model to Examine How Destination Image, Attitude, And Motivation Affect the Future Behavior of Tourists. Leisure Sci. 31 (3):215- 236.

Marmo, R. and Baggio, R. (2017). Building Confidence Measures for Tourist Destination Choice. International Journal of Tourism Sciences, 17(1):61-66.

Muhoho-Minni, P. and Lubbe, B. A. (2017). The Role of the Media in Constructing a Destination Image: The Kenya Experience. Communicatio, 43(1):58-79.

Özer, S.U. (2015). İstanbul'da Faaliyet Gösteren Beş Yıldızlı Otel İşletmelerinin Müşteri Sadakat Programlarının İçerik Analizi. Muğla Sıtkı Koçman Üniversitesi İktisadi ve İdari Bilimler Fakültesi Ekonomi ve Yönetim Araştırmaları Dergisi, 4(1).

Pesonen, J. and Pasanen, K. (2017). A Closer Look at Tourist Information Search Behaviour When Travelling Abroad: What Is the Role of Online Marketing in Choice of Destination? In Information and Communication Technologies in Tourism 2017 (pp. 431443). Springer, Cham.

Pfaffenberg, C. and J. Burnett, (2007), Users of Hotel Website Reservation Systems: A Demographic Profile, The Consortium Journal, 11 (2): 51-60.

Sarı, Y. ve Kozak, M. (2005). Turizm Pazarlamasında İnternetin Etkisi: Destinasyon Web Siteleri İçin Bir Model Önerisi, Akdeniz İ.İ.B.F. Dergisi, (9):248-271. 